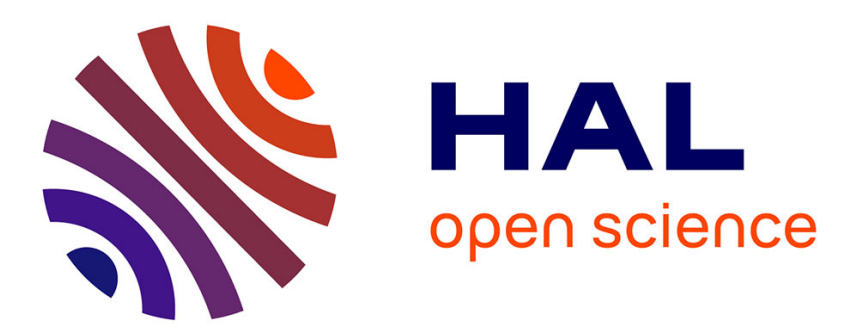

\title{
Genetic identification of intestinal microsporidia species in immunocompromised patients in Tunisia.
}

Najla Chabchoub, Rim Abdelmalek, Fethi Mellouli, Fakher Kanoun, Marc Thellier, Aïda Bouratbine, Karim Aoun

\section{- To cite this version:}

Najla Chabchoub, Rim Abdelmalek, Fethi Mellouli, Fakher Kanoun, Marc Thellier, et al.. Genetic identification of intestinal microsporidia species in immunocompromised patients in Tunisia.. American Journal of Tropical Medicine and Hygiene, 2009, 80 (1), pp.24-7. 10.4269/ajtmh.2009.80.24 . pasteur-00859425

\section{HAL Id: pasteur-00859425 \\ https://hal-riip.archives-ouvertes.fr/pasteur-00859425}

Submitted on 8 Sep 2013

HAL is a multi-disciplinary open access archive for the deposit and dissemination of scientific research documents, whether they are published or not. The documents may come from teaching and research institutions in France or abroad, or from public or private research centers.
L'archive ouverte pluridisciplinaire HAL, est destinée au dépôt et à la diffusion de documents scientifiques de niveau recherche, publiés ou non, émanant des établissements d'enseignement et de recherche français ou étrangers, des laboratoires publics ou privés. 


\title{
Genetic Identification of Intestinal Microsporidia Species in Immunocompromised Patients in Tunisia
}

\author{
Najla Chabchoub, Rim Abdelmalek, Fethi Mellouli, Fakher Kanoun, Marc Thellier, Aïda Bouratbine, \\ and Karim Aoun* \\ Laboratoire de Recherche 05-SP-03, Laboratoire de Parasitologie, Institut Pasteur de Tunis, Tunis, Tunisia; Service des Maladies \\ Infectieuses, Hôpital de la Rabta, Tunis, Tunisia; Service d'Immuno-hématologie Pédiatrique, Centre de Greffe de Moelle \\ Osseuse, Tunis, Tunisia; Laboratoire de Parasitologie-Mycologie, Hôpital de la Pitié-Salpétrière, Unité INSERM 511, \\ Université Paris VI Pierre et Marie Curie, Paris, France
}

\begin{abstract}
Stool samples from 86 immunocompromised patients (51 human immunodeficiency virus (HIV)-infected patients and 35 patients with haematologic malignancies) were systematically screened for intestinal microspordiosis by microscopic examination and polymerase chain reaction (PCR) using universal primer V1/PMP2. Nine samples $(10.5 \%)$ showed amplification with the predictive size of fragment (6 from HIV-infected patients and 3 from patients with myeloma). Only 5 out of them (all HIV-infected patients) were revealed positive by microscopy. By means of amplicons fragment size, species-specific primers (V1/EB450, V1/IS500) and sequencing, 3 microsporidia species were for the first time identified in Tunisia: Enterocytozoon bieneusi (3 isolates), Encephelitozoon intestinalis (2 isolates), and Encephalitozoon hellem (1 isolate). Systematic use of such sensitive and discriminative molecular tools will contribute to determining the true prevalence of microsporidiosis in Tunisia and to better management of infected immunocompromised subjects.
\end{abstract}

\section{INTRODUCTION}

Intestinal microsporidiosis ranks among the most common causes of diarrhea among immunocompromised individuals. ${ }^{1}$ Most cases have been documented in patients infected with the human immunodeficiency virus (HIV) and only a few of them have been related to other immunosupressive etiologies. ${ }^{2}$ Diagnostic procedures of intestinal microsporidiosis have been markedly improved by the use of Weber's chromotropebased stain. ${ }^{3}$ Molecular-based techniques, such as polymerase chain reaction (PCR), are mainly used for positive case confirmation and/or species differentiation. ${ }^{4}$ Despite the important implications of microsporidia species identification on the clinical and therapeutic management of patients, the corresponding data are still rare. ${ }^{5}$ Enterocytozoon (E.) bieneusi and Encephalitozoon (E.) intestinalis are the two species responsible for the majority of infections in man. ${ }^{6}$ Published human cases caused by Encephalitozoon hellem and Encephalitozoon cuniculi are rare. ${ }^{6,7}$

In Tunisia, microsporidia parasites have been found in both immunocompetent and immunocompromised diarrheal subjects. ${ }^{89}$ However, no species identification has been performed yet. The purpose of this study was to detect and to identify microsporidia species in stools from immunocompromised Tunisian patients.

\section{MATERIALS AND METHODS}

Stool samples. Stool samples were collected from 86 immunocompromised Tunisian patients; $51 \mathrm{HIV}$-infected patients, and 35 suffering from haematologic malignancies (HM) ( 8 chronic myeloid leukaemia, 8 myeloma, 7 acute lymphoid leukaemia, 6 chronic lymphoid leukaemia, and 6 Hodgkin disease). Fifty-four patients were diarrheic. Collections were

* Address correspondence to Karim Aoun, LR "Parasitoses Émergentes", Laboratoire de Parasitologie, Institut Pasteur de Tunis, 13 Place Pasteur, BP 74, 1002 Tunis Belvedère, Tunisia. E-mail: karim.aoun@fmt.rnu.tn done, after individual consent, within the framework of routine screening for opportunistic pathogens. All specimens were systematically investigated for microsporidia infection by light microscopy and PCR.

Weber's modified trichrome stain. Each stool specimen was mixed with $10 \%$ formalin (1:3 ratio) then filtered through sieves with pore diameters of $400 \mu \mathrm{m} ; 3 \mathrm{~mL}$ of ether were added to the filtrate. The mixture was shaken for a minute and centrifuged at 2,000 $\mathrm{g}$ for 2 minutes. From pellet a thin smear was prepared on a glass slide, dried, fixed with methanol for 5 minutes, and stained with Weber's modified trichrome stain (MTS), as adapted by Kokoskin and others. ${ }^{10}$ Each stained smear was examined using Leitz Laborlux binocular microscopes (Wetzlar, Germany) with built-in illumination and a total magnification of $1000 \times(10 \times$ widefield eyepieces and a $100 \times$ oil immersion lens). Negative results were reported after at least 10 minutes of examination.

DNA extraction. The DNA was extracted from frozen samples using the QIAamp DNA Tissue Kit (Qiagen Inc, Germany). Briefly, $200 \mu \mathrm{L}$ of stool suspension was washed three times in phosphate-buffered-saline (PBS) solution by centrifugation at $12,000 \mathrm{~g}$ for 5 minutes. The final pellet was suspended in $180 \mu \mathrm{L}$ of tissue lysis buffer and incubated with proteinase $\mathrm{K}$ for 2 hours at $55^{\circ} \mathrm{C}$. The manufacturer's recommendations were followed for purification and elution of DNA, which was then stored at $-20^{\circ} \mathrm{C}$ until analyzed.

PCR amplifications. Two sets of PCR primers were used in this study as described in previous reports. The forward primer V1: 5'CACCAGGTTGATTCTGCCTGAC-3' and the reverse primer PMP2: 5'-CCTCTCCGGAACCAAACCCTG-3') amplify the small-subunit ribosomal DNA (SSU-rDNA) of four human microsporidia, E. bieneusi, E. intestinalis, E. cuniculi, and E. hellem. ${ }^{11}$ Samples proved positive by V1/PMP2 primers with predictive size fragment about 250 to $279 \mathrm{bp}$, have been subject to two other PCR, using species-specific primers, V1/EB450 (5'-ACTCAGGTGTTATACTCACGTC-3') and V1/SI500 (5'-CTCGCTCCTTTACACTCG-3') to differentiate E. bieneusi infection from $E$. intestinalis infection, respectively. ${ }^{12}$

Amplification for all PCR was done in $50 \mu \mathrm{L}$ reaction mixtures under the following conditions: $1 \times$ PCR buffer, $2.5 \mathrm{mM}$ 
TABLE 1

Light microscopy and PCR results for nine patients with intestinal microspridiosis

\begin{tabular}{|c|c|c|c|c|c|c|}
\hline \multirow[b]{2}{*}{ Patient no. } & \multirow[b]{2}{*}{ Clinical and biologic status* } & \multicolumn{2}{|c|}{ Results of } & \multicolumn{2}{|c|}{ Results of PCR using primer pair } & \multirow[b]{2}{*}{ Sequencing result } \\
\hline & & MTS & $\mathrm{PCR} \dagger$ & $\mathrm{V} 1 / \mathrm{EB} 450$ & V1/SI500 & \\
\hline 1 & $\mathrm{HIV}(\mathrm{CD} 4 \ddagger=23)$ & - & + & + & - & E. bieneusi \\
\hline 2 & $\mathrm{HIV}(\mathrm{CD} 4=\mathrm{ND} \S)$ & + & + & - & + & E. intestinalis \\
\hline 3 & $\mathrm{HIV}(\mathrm{CD} 4=46)$ & + & + & - & - & ND \\
\hline 4 & $\mathrm{HIV}(\mathrm{CD} 4=21)$ & + & + & - & - & ND \\
\hline 5 & $\mathrm{HIV}(\mathrm{CD} 4=22)$ & + & + & + & - & E. bieneusi \\
\hline 6 & $\mathrm{HIV}(\mathrm{CD} 4=44)$ & + & + & + & - & E. bieneusi \\
\hline 7 & Myeloma & - & + & - & - & E. hellem \\
\hline 8 & Myeloma & - & + & - & + & E. intestinalis \\
\hline 9 & Myeloma & - & + & - & - & ND \\
\hline
\end{tabular}

, human immunodeficiency virus infection.

$\dagger$ Result of polymerase chain reaction (PCR) using primer pair V1/PMP2.

$\leftarrow \mathrm{CD} 4+\mathrm{T}$ cells count per $\mu \mathrm{L}$

$\S \mathrm{ND}=$ not determined.

of $\mathrm{MgCl}_{2}, 20$ pmol of each primer, $200 \mu \mathrm{M}$ concentrations of each dNTP, $1.25 \mathrm{U}$ of Goldstar Taq DNA polymerase (Applied biosystem, Roche, Switzerland), and $10 \mu \mathrm{L}$ of the DNA. Amplification consisted of 5 minutes at $94^{\circ} \mathrm{C}$ followed by 35 cycles of 45 seconds at $94^{\circ} \mathrm{C}, 30$ seconds at $55^{\circ} \mathrm{C}$, and 45 seconds at $72^{\circ} \mathrm{C}$; a final phase of extension at $72^{\circ} \mathrm{C}$ for 10 minutes. The amplified products were separated by electrophoresis on a $2 \%$ agarose gel and visualized after staining with ethidium bromide.

Each set of experiments included a negative (distilled water) and two positive PCR controls. The positive controls were DNA template extracted from positive stool specimens infected with E. bieneusi and E. intestinalis kindly provided by Marc Thellier from Pitié-Salpetrière Hospital, Paris-France.

DNA sequencing analysis. All DNA fragments obtained by universal primers V1/PMP2 were sequenced. The PCR products were purified using GenElute PCR Clean-Up kit (Sigma, St. Louis, MO). Sequencing reactions were performed directly on the amplification products using ABI Prism 377 DNA Sequencer (Applied Bio System, Foster City, CA). The sequences were compared with those available in the GenBank Database with the BlastN program located at (http://www. ncbi.nlm.nih.gov).

\section{RESULTS}

Examination of the 86 stool samples by microscopy showed microsporidian spores in 5 samples $(5.8 \%)$, all 5 out of 51 (9.8\%) HIV-infected patients. Using universal primers V1/ PMP2, 9 out of $86(10.5 \%)$ stool samples showed a positive amplification. Considering that technique, the prevalence rate of microsporidia infection were $11.8 \%$ (6 out of 51 ) and $8.6 \%$ (3, all with myeloma, out of 35) for, respectively, HIV and HM groups (Table 1). Of the nine 7 were diarrheic.

Among the 9 samples that proved positive by PCR, microsporidia species identification was successfully achieved in 6 isolates. A 250 bp DNA fragment, suggesting infection with $E$. bieneusi, was obtained from stools of $3 \mathrm{HIV}$-infected patients (Figure 1). In those samples, amplification of 353 bp DNA fragment was achieved with E. bieneusi-specific primers and no amplification was obtained with $E$. intestinalis-specific primers. The 3 sequences had $98-99 \%$ sequence identity with $E$. bieneusi (Genbank accession no. AY257180). A 270 bp DNA fragment, suggesting infection with $E$. intestinalis, was amplified from stool specimens from 2 patients (1 HIV patient, 1 patient with myeloma) (Figure 1). A 375 bp DNA fragment was obtained from these samples after PCR with E. intestinalis-specific primers (Figure 2). The 2 amplicons had 96\% and 99\% sequence identity with E. intestinalis (Genbank accession no. EU436735). A 279 bp DNA fragment was amplified in one sample from a myeloma patient, suggesting infection with E. hellem. This sample, negative by both E. intestinalis and E. bieneusi-specific primers, had $98 \%$ sequence identity with E. hellem (Genbank accession no. L19070). In the remaining 3 positive samples (2 HIV and 1 myeloma patients), the length of the obtained fragment was too weak for further analysis. These 3 samples revealed negative by both species-specific primers (Table 1).

\section{DISCUSSION}

As previously reported, PCR using universal primers V1/PMP2 detected more intestinal microsporidia infections ( 9 cases) than did light microscopy ( 5 cases $).{ }^{13}$ The difference is probably a result of the limited sensitivity of light microscopy



FIGURE 1. Agarose gel electrophoresis of polymerase chain reaction (PCR) products with V1/PMP2 primers stained with ethidium bromide. Lane 1,100-basepair DNA ladder (Amersham, UK); lane 2, positive sample of E. bieneusi; lane 3, positive control of E. bieneusi; lane 4, positive control of $E$. intestinalis; lane 5,6 , positive sample of E. intestinalis; lane 7, positive sample of E. hellem; lane 8, negative control. 


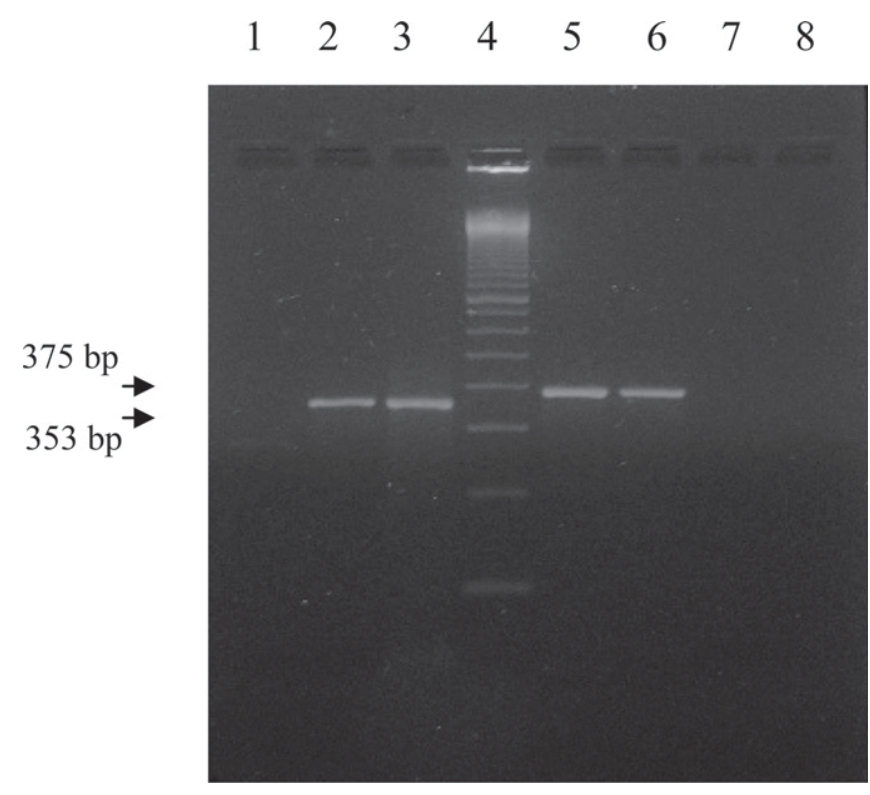

FIgURE 2. Agarose gel electrophoresis of polymerase chain reaction (PCR) products obtained using species-specific primers V1/ EB450 and V1/SI500. Lane 1, negative samples of E. bieneusi; lane 2, positive sample of E. bieneusi; lane 3, positive control of E. bieneusi; lane M, molecular size marker of $100 \mathrm{pb}$ (Amersham, UK); lane 5, positive control of E. intestinalis; lane 6, positive samples of E. intestinalis; lane 7, negative samples of E. intestinalis; lane 8, negative control.

estimated to be between $10^{4}$ and $10^{6}$ spores per $\mathrm{g}$ of stool, whereas PCR can detect parasitic loads of $10^{2}$ spores per $\mathrm{g}$ of stool..$^{14}$ This better sensitivity of PCR allows us to establish a higher prevalence rate $(10.5 \%)$ of intestinal microsporidiosis in Tunisia in comparison to those reported in previous studies. ${ }^{8}$

The distinction between Encephalitozoon and Enterocytozoon in light microscopy is often impossible because of the very small size of the microsporidia spores ${ }^{10}$; In fact, spores of E. bieneusi average $1.5 \times 1.0 \mu \mathrm{m}$ and those of E. intestinalis $2.2 \times 1.2 \mu \mathrm{m} .{ }^{1,6}$ The PCR and sequencing, which represent the reference tools for species identification,,$^{13,15}$ are here used for the first time in North Africa to identify the Microsporidia species found in stool samples from a group of 86 immunocompromised Tunisian patients. Such parasites characterization is now necessary for an appropriate therapeutic management of patients. In fact, if albendazole is effective against Encephalitozoon spp., only fumagillin have shown to be effective against E. bieneusi. ${ }^{5}$

The species identification was successfully performed in 6 isolates, 3 corresponded to E. bieneusi, 2 to E. intestinalis, and the last to E. hellem (Table 1, Figures 1 and 2). As largely described, E. bieneusi was predominant in HIV-infected patients ( 3 out of 4 identifications). ${ }^{6,12}$ Encephalitozzon hellem and E. intestinalis were identified in 2 patients with $\mathrm{HM}$, it is to our knowledge among the rare reports of Encephalitozoon spp. in stools from non-HIV infected patients. ${ }^{6}$ In fact, E. intestinalis has been mainly documented in HIV-infected patients, ${ }^{16}$ whereas E. hellem has been more described as infecting the epithelial surfaces of ocular and respiratory tissues. ${ }^{17,18}$

Received July 4, 2008. Accepted for publication August 20, 2008.

Acknowledgments: The authors thank Saloua Laddab, Essia Ben Hassen, Mohamed Bejaoui, and Tarak Ben Othmane from the Bone
Marrow Transplant Center of Tunis; Samah Aissa and Taoufik Ben Chaabene from the Department of Infectious Diseases, and Neyla Ben Romdhane from the Department of Haematology of La Rabta Hospital-Tunis, and all the physicians in charge of the patients for their help in the collection of stools and clinical data. The authors are grateful to Mrs. Rim Essid, Olfa Souissi, Najet Zallagua, and Mr. Adel Rhim from Pasteur Institute of Tunis, and Mr. Sylvestre Billigui from Pitié-Salpétrière hospital, Paris-France, for their technical collaboration.

Financial support: This study was supported by the Ministry of Higher Education, Research and Technology, Tunisia, in the setting of the Research Lab "Parasitoses emergentes" LR 05-SP-03.

Authors' addresses: Najla Chabchoub, Aïda Bouratbine, and Karim Aoun, LR "Parasitoses Émergentes", Laboratoire de Parasitologie, Institut Pasteur de Tunis, 13 Place Pasteur, BP 74, 1002 Tunis Belvedère, Tunisia, Tel: 216-71-890-827, Fax: 216-71-791-833. Rim Abdelmalek and Fakher Kanoun, Service des Maladies Infectieuses, la Rabta, 1007 Jebbari Tunis, Tunisia, Tel/Fax: 216-71-578-833. Fethi Mellouli, Service d'Immuno-Hématologie Pédiatrique, Centre de Greffe de Moelle Osseuse, 2 rue Djebel Lakhdhar, Tunis, Tunisia. Marc Thellier, Laboratoire de Parasitologie-Mycologie, Hôpital de la Pitié Salpétrière, 47-83 Boulevard de l'Hôpital, 75651 Paris, France, Tel: 33-01-42-16-01-84, Fax: 33-1-42-16-01-65.

Reprint requests: Karim Aoun, LR "Parasitoses Émergentes", Laboratoire de Parasitologie, Institut Pasteur de Tunis, 13 Place Pasteur, BP 74, 1002 Tunis Belvedère, Tunisia, Tel: 216-98-699-512, Fax: 216-71-791-833, E-mail: karim.aoun@fmt.rnu.tn.

\section{REFERENCES}

1. Molina JM, Sarfati C, Beauvais B, Lemann M, Lesourd F, Ferchal F, Casin I, Lagrange P, Modigliani R, Derouin F, Modai J, 1993. Intestinal microsporidiosis in human immunodeficiency virusinfected patients with chronic unexplained diarrhea: prevalence and clinical and biologic features. $J$ Infect Dis 167: 217-221.

2. Guerard A, Rabodonirina M, Cotte L, Liguory O, Piens MA, Daoud S, Picot S, Touraine JL, 1999. Intestinal microsporidiosis occurring in two renal transplant recipients treated with mycophenolate mofetil. Transplantation 5: 699-707.

3. Weber R, Bryan RT, 1992. Improved light-microspridial detection of microsporidia spores in stool and duodenal aspirates. $N$ Engl J Med 326: 161-166.

4. Katzwinkel-Wladarsch S, Lieb M, Helse W, Loscher T, Rindier H, 1996. Direct amplification and species determination of microsporidian DNA from stool specimens. Top Med Int Health 1: 373-378.

5. Didier ES, 1997. Effects of Albendazole, Fumagillin, and TMP-470 on microsporidial replication in vitro. Antimicrob Agents Chemother 41: 1541-1546.

6. Weber R, Bryan RT, Schwartz DA, Owen RL, 1994. Human microsporidial infections. Clin Microbiol Rev 7: 426-461.

7. Franzen C, Schwartz DA, Visvesvara GS, Muller A, Schwenk A, Salzberger B, Fatkenheur G, Hartmann P, Diehl V, Schrappe M, 1995. Immunologically confirmed disseminated asymptomatic Encephalitozoon cuniculi infection of gastrointestinal tract in patient with AIDS. Clin Infect Dis 21: 1480-1484.

8. Belhadj S, Kallel K, Boussen N, Ghobatini A, Bejoui M, Ben salem N, Ziribi A, BenChaabane T, Chaker E, 1999. Places des cryptosporidies et des microsporidies dans les diarrhées des immunodéprimés. Tunis Med 77: 638-643.

9. Aoun K, Bouratbine A, Darty A, Biligui S, Ben Ismail R, 1997. Présence de microsporidies intestinales en Tunisie: à propos d'un cas. Bull Soc Path Ex 90: 176.

10. Kokoskin E, Gyorkos TW, Camus A, Cedilotte L, Purtill T, Ward B, 1994. Modified technique for efficient detection of microsporidia. J Clin Microbiol 36: 1974-1975.

11. Fedorko DP, Nelson NA, Cartwright CP, 1995. Identification of microsporidiabin stool specimens by using PCR and restriction endonucleases. J Clin Microbiol 33: 1739-1741.

12. Coyle CM, Wittner M, Kotler DP, Noyer C, Orenstein JM, Tanowitz HB, Weiss LM, 1996. Prevalence of microsporidi-osis due to 
Enterocytozoon bieneusi and Encephalitozoon (Septata) intestinalis among patients with AIDS-related diarrhea: determination by chain polymerase reaction to the microsporidian small-subunit rRNA gene. Clin Infect Dis 23: 1002-1006.

13. Müller A, Stellerman K, Hartmann P, Scharppa M, Fathenheuer G, Salzberger B, Diehl V, Franzen C, 1999. A powerful DNA extraction method and PCR for detection of mocrosporidia in clinical stool specimens. Clin Diagn Lab Immunol 2: 243-246.

14. Didier ES, Orenstein JM, Aldras A, Bertucci D, Rogers LB, Janney FA, 1995. Comparaison of three methods for detecting microsporidia in fluids. J Clin Microbiol 33: 3138-3145.

15. Dowd SE, Gerba CP, Pepper IL, 1998. Confirmation of human-pathogenic microsporidia Enterocytozoon bieneusi, Encephalitozoon intestinalis and Vittaforma corneae in water. Appl Environ Microbiol 64: 3332-3335.
16. Cali A, Kotler P, Orenstein JM, 1993. Septata intestinalis N. G., N. sp., an intestinal microsporidian associated with chronic diarrhea and dissemination in AIDS patients. J Eukaryot Microbiol 40: $101-112$.

17. Didier ES, Didier PJ, Friedberg DN, Stenson SM, Orenstein JM, Yee RW, Tio FO, Davis MR, Vossbrinck C, Millichamp N, Shadduck JA, 1991. Isolation and characterization of a new human microsporidia, Encephalitozoon hellem (n. sp), from three AIDS patients with keratoconjunctivitis. J Infect Dis 163: 617-621.

18. Schwartz DA, Visvesvara GS, Leitch GJ, Tashjian L, Pollack M, Holden J, Bryan RT, 1993. Pathology of symptomatic microsporidial (Encephalitozoon hellem) bronchiolitis in AIDS: a new respiratory pathogen diagnosed from lung biopsy, bronchoalveolar lavage, sputum, and tissue culture. Hum Pathol 24: 937-943. 